\title{
Zafar, Samra (with Meg Masters). (2019). A Good Wife: Escaping the Life I Never Chose - A Memoir. Toronto: Harper Collins.
}

\author{
Reviewed by: Cora Desmeules, MacEwan University
}

The book "A Good Wife," is a memoir about Samra Zafar's experience of surviving an abusive marriage. Zafar highlights many components of her life that she thought integral to explaining the intricacies of abuse, and the many forms in which it can be relayed. This book not only describes the ways in which Zafar was a victim of emotional and physical abuse for nearly a decade, but also explains how she was able to escape her abusive marriage, which was primarily through her education at the University of Toronto. For Zafar, education played a central role in her escaping her marriage as it was how she was initially introduced to the word abuse, and how the cycle of abuse operates. Although she was involved in an arranged marriage, Zafar mentions that "victims and abusers come from all cultures, all races, all religions, all socio-economic backgrounds and all walks of life (p. 326). The intersection of race and gender is important to acknowledge, as marginalized women have a higher chance of suffering abuse from family members. Abuse can occur in many different forms, which can make it difficult to detect. This is one reason why Zafar has become an advocate for educating women on the topic of abuse. She acknowledges that for many years she did not realize there was anything wrong in her in-law family's treatment of her, as abuse was not something she was educated on.

There are many reasons why victims feel they have no alternatives when they are involved 
in an abusive relationship, such as no reliable income, low self-esteem, or scare tactics such as threats from the abuser. One reason why Zafar struggled to leave her marriage was because abuse was normalized through her culture, community, and her husband's family whom she was forced to live with. Amma, her mother-in-law says to Zafar,

It is perfectly permissible in Islam for a man to hit his wife. It's written in the Koran. And other women have it much worse than you do, but they still stay. It is a good wife's duty to make things better. After all, you need to keep your family together. If you were ever to leave, the government would give Aisha to Ahmed since you have no education and no money" (p. 127).

Scare tactics such as this one was often used against Zafar in order to keep her silenced and submissive to her abusers. Zafar's culture and family put continuous pressure on her to make her marriage work, as a failed marriage was seen as the woman's fault. If a woman did divorce her husband, she was seen as promiscuous, and this was something that was reiterated to her through her immediate and in-law family. What was expected of Zafar was made clear, her role as a woman, wife, and mother, was to keep her family together and keep her husband happy. Although her marriage was arranged, Zafar mentions that "the vast majority of domestic abuse occurs between men and women who began their relationships as love matches" (pg. 326). This fact is important to acknowledge as her religion was not the reason why she was abused, but it did play a role in her staying in her marriage as long as she did.

Furthermore, as the oldest child in her family Zafar witnessed her parents' marriage and how it was tumultuous at times. Recalling on her dad and mom's marriage, she writes, "when he got angry his rages were ferocious. More than once, he slapped or pushed her... My parents did have their happy times. After the worse of their fights, harmony always settled again" (pp. 21- 
22). Witnessing her father's anger and physical violence toward her mother normalized abusive behaviours for Zafar at a young age. Although her father had abusive tendencies, her parents always reconciliated. Witnessing episodes such as the one described normalized the fact that husbands were allowed to hit their wives with no repercussions, and the fact that her parent's marriage would always return to a happy state may have led Zafar to believe that her marriage would operate the same. This false hope can lead victims to consistently return to a relationship where they are abused, especially when their abusers try to minimize their actions with excuses and make up for it with gifts or apologies. Abuse can be inflicted in various different ways: physical, psychological, verbal, and emotional. Zafar writes, "on average, an abused woman returns to her abuser seven times before she is able to make the final split" (p. 326).

Zafar recognizes her education as being integral to not only learning what abuse was, but also contributing to her building the courage to leave her abusive marriage and family life. Once she started University, Zafar began to gain confidence in herself as an individual as she began to realize that her actions were not monitored at school. It was through the University of Toronto that Zafar also gained access to counsellors, which was helpful because they were counsellors that were not a part of her traditional community. Being in Canada, where many people hold western ideals, she was able to get other people's perspectives on her life situation that would otherwise not have been available to her via her community. This is where she gained the knowledge that what was happening to her was, indeed, not normal, nor was it acceptable. Despite her unhappiness, her complaints to her parents and protests to Amma and Ahmed alike, Zafar had always assumed that if she "managed things better, been a good wife, a better daughter-in-law, a more compliant 
women, I could have prevented her husband's outbursts and tempered his anger" (p. 230). The counsellor helped Zafar understand that this was a false belief, as the victim is never to blame for the abuse they suffer. Blaming the victim only further worsens their feelings of shame and prevents them from gaining any self-confidence, which is what the abuser intends to do. The recognition of the cycle of abuse, and the characteristics of what an abusive husband looks like allowed Zafar to learn that her marriage was not as loving as her husband led her to believe, but rather that he was possessive and controlling to the point of violence.

For many years after her separation from her husband, Zafar felt deep shame as divorce was taboo in her religion and therefor in her community. After Zafar had made the official police report against Ahmed, she was praised by the police officers for the bravery it took in order to make an official complaint and tell her story to them. This was in contrast to the response she received from her mother, whom was worried about the family's honour and discussed "the deep shame this news would bring to them" (p. 282). University was integral to Zafar gaining her confidence, because it gave her a support system outside of her traditional community. Explaining the importance of a community, Zafar writes, "What survivors need- beyond shelters, police and counselling- is a sense of belonging. A community of support. Someone to teach them how to walk so that they can eventually run and fly" (p. 328). The thought of being alone is daunting, especially to abuse victims as their self-esteem is usually completely deteriorated with intense feelings of self-doubt. The University of Toronto gave Zafar the support she needed to successfully create a life on her own while raising and supporting her two daughters. Although shelters and counselling support are effective ways to help abuse victims build a better life for themselves, they are 
ultimately just reactive measures. Zafar believes that the answer of preventing abuse "lies in education, providing everyone with a knowledge of what abuse looks like and how one can find oneself in an abusive relationship" (p. 330). This is the message that she is trying to convey to readers with her memoir, that abuse can indeed be combatted with the proper education of young men and women.

The intended audience that Zafar wants to reach are people involved in human resource jobs and the humanities in general. This can range from social workers, teachers, sociologists, psychologists, lawyers, nurses, and the general populace. I thoroughly enjoyed reading "A Good Wife" and found it to be an engaging book while also being extremely informative. I think this book is beneficial for any person to read, as it promotes conversation about a topic that many people feel uncomfortable discussing: abuse. 